DOI: https://doi.org/10.47405/mjssh.v6i9.1034

\begin{tabular}{|c|c|}
\hline 4 & Malaysian Journal of Social Sciences and Humanities (MJSSH) \\
\hline $\begin{array}{l}\text { Malaysian Juoural of } \\
\text { Social ccciecces and }\end{array}$ & Volume 6, Issue 9, September 2021 \\
\hline (MJ-sSH) & e-ISSN : 2504-8562 \\
\hline & $\begin{array}{l}\text { Journal home page: } \\
\text { www.msocialsciences.com }\end{array}$ \\
\hline
\end{tabular}

\title{
Cabaran dalam Proses Kutipan Data Kaedah Kualitatif Ketika Perintah Kawalan Pergerakan (PKP) dan Pandemik Covid-19
}

\author{
Sulaiman Tahajuddin', Abdul Wahid Mohd Kassim¹, Jainurin Justine1, Intan Soliha Ibrahim² \\ 1Fakulti Perniagaan, Ekonomi dan Perakaunan, Universiti Malaysia Sabah (UMS) \\ ${ }^{2}$ Fakulti Sains Sosial dan Kemanusiaan, Universiti Malaysia Sabah (UMS) \\ Correspondence: Sulaiman Tahajuddin (sulaiman@ums.edu.my)
}

\begin{abstract}
Abstrak
Kajian ini bertujuan untuk memahami dan menerangkan mengenai cabaran atau kesukaran yang berlaku dalam proses mengutip data bagi kajian yang menggunakan kaedah kualitatif ketika Perintah Kawalan Pergerakan (PKP) sedang berjalan disebabkan oleh pandemik Covid-19 di Malaysia. Sama ada kaedah kuantitatif mahupun kualitatif, kedua-duanya memerlukan data yang bersifat tulen, lengkap dan berkualiti. Untuk tujuan tersebut, maka proses pengutipan data memerlukan tatacara kutipan data dilakukan dengan berhati-hati dan pada masa yang sama mengikut prosedur terbaik. Kajian ini telah memilih satu entiti syarikat berkaitan kerajaan (GLC) dan satu entiti pertubuhan bukan kerajaan (NGO) sebagai kajian kes untuk mencapai objektif kajian. Dapatan kajian mendapati terdapat isu dan cabaran yang agak berbeza dalam proses kutipan data melibatkan GLC dan NGO dalam konteks kajian menggunakan kaedah kualitatif. Entiti NGO didapati lebih terbuka dan bekerja sama berbanding entiti GLC dalam proses tersebut. Hasil kajian menunjukkan bahawa data yang dikutip daripada NGO adalah lebih komprehensif dan berkualiti berbanding dengan GLC. Ini menunjukkan bahawa, terdapat banyak isu dan cabaran yang dihadapi dalam proses mengumpul data daripada GLC berbanding daripada NGO ketika PKP Covid-19 di Malaysia.
\end{abstract}

Kata kunci: Covid-19, isu dan cabaran, kualitatif, kutipan data, GLC, NGO

\section{The Challenges in Qualitative Method Data Collection Process during the Covid-19 Movement Control Order (MCO)}

\begin{abstract}
This study aims to understand and explain the issues and challenges encountered in the process of data collection for the research based on the qualitative method during the Movement Control Order (CMO) due to Covid-19 Pandemic in Malaysia. Regardless of quantitative or qualitative methods, both require the data that is genuine, comprehensive and quality in nature. Therefore for that purpose, the data collection process needs to be carried out carefully, and employing the best procedure at the same time. This study chose a government link company (GLC) and a non-governmental organization (NGO) as a case study in order to achieve the aim of the study. The findings of the study demonstrate the differences in issues and challenges that had been faced in the data collection process involving the two entities namely GLC and NGO within the context of study employs the qualitative data collection method. The results reveal that the data collected from the NGO is more comprehensive and quality as compared to the data collected from the GLC. This suggests that there are more issues and challenges
\end{abstract}


being faced in data collection process involving the GLCs during the Covid-19 CMO in Malaysia as compared to NGOs.

Keywords: Covid-19, issues and challenges, qualitative, data collections, GLCs and NGOs

\section{Pengenalan}

Kajian ini bertujuan untuk memahami dan menerangkan mengenai isu-isu dan cabaran yang berlaku dalam proses mengutip data bagi kajian yang menggunakan kaedah kualitatif ketika Perintah Kawalan Pergerakan (PKP) sedang berjalan disebabkan oleh pandemik Covid-19 di Malaysia. Seperti yang diketahui umum, Pandemik Covid-19 dikatakan bermula di Wuhan, China pada akhir tahun 2019 dan seterusnya menular ke seluruh dunia pada kadar jangkitan yang membimbangkan. Di Malaysia, Pandemik Covid-19 dikatakan telah menjejaskan ekonomi negara ini pada skala yang signifikan bila kerajaan melaksanakan tindakan drastik mengawal pergerakan aktiviti melibatkan manusia dalam semua sektor khususnya sektor ekonomi dan sosial (Tahajuddin, 2021; Tahajuddin \& Sulaiman, 2021). Kawalan pergerakan ini dikenali sebagai Perintah Kawalan Pergerakan (PKP) yang telah dilaksanakan secara berperingkat dan pelbagai siri seperti Perintah Kawalan Pergerakan Diperketat (PKPD), Perintah Kawalan Pergerakan bersyarat (PKPB) dan Perintah Kawalan Pergerakan Pemulihan (PKPP). Sejak itu , Pandemik Covid-19 mula mendapat perhatian daripada para pengkaji yang melihatnya daripada pelbagai sudut termasuklah kesannya kepada ekonomi dan kehidupan sosial masyarakat khususnya pekerjaan, kesihatan dan pendidikan (Contohnya, Abdul Rashid, Hassan \& Ahmad, 2020; Foo, Chin \& Phuah, 2020; Karim, Haque, Anis \& Ulfy, 2020; Khan \& Hashim, 2020; Mokhtar, Yazid \& Shamsudin, 2020; Razak, 2020; Shah et al., 2020).

Majoriti kajian tersebut (Tahajuddin, 2021) jelas menunjukkan bahawa perlaksanaan PKP di Malaysia dan kesannya ke atas ekonomi, politik dan sosial di negara ini telah mendapat perhatian yang meluas di kalangan para pengkaji atau penyelidik. Walau bagaimanapun, seperti yang dicadangkan oleh Tahajuddin (2021), memandangkan kesan PKP dan Pandemik Covid-19 secara relatifnya adalah baharu maka masih banyak yang perlu dikaji dan diketahui mengenainya khususnya dalam bidangbidang terkhusus seperti kesan ke atas sistem dalaman organisasi, ke atas sistem dan amalan pengurusan dan pelbagai lagi. Pada masa yang sama, kajian dan penelitian terhadap hasil kajian dan penulisan melibatkan kesan pandemik ini di Malaysia mahupun sebahagian besar di peringkat global menunjukkan belum ada kajian yang mengkhusus bagaimana PKP dan juga Pandemik Covid-19 ini telah memberi kesan ke atas aktiviti penyelidikan secara umum, dan khususnya juga ke atas aktiviti pengumpulan data penyelidikan.

Dalam aktiviti melibatkan penyelidikan tanpa mengira sama ada ianya menggunakan pendekatan atau kaedah kuantitatif atau kualitatif maka satu elemen dalam proses menyelidik yang sangat penting adalah proses pengutipan data. Sama ada untuk tujuan memperkukuhkan atau membuktikan kesahihan satu teori atau hipotesis (khususnya dalam kaedah kuantitatif), mahupun untuk memahami satu fenomena melalui kajian kes (dalam kaedah kualitatif), maka tahap kualiti pembuktian atau pemahaman itu akan bergantung kepada hasil daripada kualiti dan kuantiti data yang telah dikutip oleh penyelidik yang terlibat. Dalam erti kata lain, para penyelidik perlu memastikan bahawa proses pengutipan data mestilah dilakukan secara teliti dan berhati-hati agar kualiti dan kuantiti data yang dikutip itu adalah memenuhi kriteria yang diperlukan dalam penyelidikan. Persoalan utama di sini ialah, dalam keadaan wujudnya PKP yang jelas akan menyebabkan proses pengutipan data tidak dapat dilakukan dalam keadaan normal, apakah kualiti dan kuantiti data yang dikutip mencukupi untuk memastikan objektif dan keabsahan penyelidikan tercapai?

Oleh itu, kajian itu bertujuan untuk melihat dan memahami bagaimanakah PKP yang dilaksanakan untuk mengawal kesan negatif Pandemik Covid-19 ini telah memberi kesan ke atas proses pengutipan data penyelidikan, khususnya penyelidikan yang menggunakan kaedah kualitatif. Adalah diharapkan agar hasil dan dapatan kajian ini akan menyumbang ke arah kefahaman yang lebih baik berkaitan proses pengutipan data dalam keadaan yang luar biasa, dan seterusnya memberi panduan untuk para 
penyelidik menghadapi keadaan tidak terjangka pada masa akan datang berkaitan proses pengutipan data.

\section{Sorotan Literatur}

Dalam bahagian ini, penyelidik membincangkan mengenai proses dan elemen-elemen yang terlibat dalam proses atau aktiviti pengutipan data kajian atau penyelidikan. Ini termasuklah perbandingan antara kaedah kuantitatif dan kualitatif dalam menjalankan kajian. Seterusnya, bahagian ini juga membincangkan mengenai pendekatan-pendekatan yang biasa dilakukan oleh penyelidik yang menggunakan kaedah kualitatif dalam mengumpul data-data kajian.

\section{Kuantitatif, Kualitatif dan Kaedah Campuran}

Seperti yang telah dinyatakan sebelum ini, Kajian ini bertujuan untuk memahami dan menerangkan mengenai isu-isu dan cabaran yang berlaku dalam proses mengutip data bagi kajian yang menggunakan kaedah kualitatif ketika Perintah Kawalan Pergerakan (PKP) sedang berjalan disebabkan oleh pandemik Covid-19 di Malaysia.

Menurut Williams (2007), dalam menjalankan penyelidikan atau kajian terdapat tiga pendekatan utama yang boleh dipilih oleh para penyelidik iaitu pendekatan bersifat kuantitatif, kualitatif dan juga kaedah campuran atau lebih dikenali dalam bahasa Inggeris sebagai mixed method. Bryant (2006) berpendapat bahawa kajian bersifat kualitatif sangat bersesuaian untuk diaplikasikan dalam menjalankan kajian yang berkaitan dengan proses perubahan organisasi. Ini berdasarkan fakta bahawa selaras dengan konsep teori Pembangunan Sosial yang berpaksikan bahawa realiti sosial itu adalah terbentuk dari pandangan dan tafsiran individu dalam masyarakat atau organisasi yang dilihat secara kolektif atau menyeluruh.

Dari segi sejarah perkembangan kajian menggunakan kaedah kualitatif, Lee dan Humphrey (2006), dan Broadbent dan Laughlin (2005) berpandangan bahawa kaedah ini sebenarnya hanya wujud secara beransur-ansur pada pertengahan abad ke-20, yang mana dikatakan bermula di United Kingdom. Menurut mereka, sebelum itu kaedah kuantitatif khususnya yang berkaitan dengan bidang perakaunan adalah dominan khususnya di Amerika Syarikat. Menurut mereka lagi, antara faktor yang mendorong kurangnya kajian bersifat kualitatif pada ketika itu adalah kerana kurangnya para tenaga pengajar seperti profesor dan juga para penyelidik lain yang berlatar belakangkan kemahiran kajian bersifat kualitatif. Seterusnya, Lee dan Humphrey (2006) mengutarakan pandangan bahawa kewujudan dan peningkatan populariti kaedah kajian kualitatif yang pada dasarnya mula berkembang di United Kingdom kerana wujudnya perasaan ketidakpuasan di kalangan para penyelidik berkaitan perkaraperkara tertentu dalam penyelidikan yang mereka jalankan. Menurut mereka yang selaras dengan pandangan Broadbent dan Laughlin (2005), sorotan literatur berkaitan perkara ini menunjukkan bahawa terdapat rungutan dan ketidakpuasan hati di kalangan para penyelidik mengenai kekurangan pada kaedah kuantitatif yang membatasi dapatan mereka dalam bidang perakaunan yang akhirnya mendorong mereka untuk menggunakan kaedah kualitatif. Sejak itu, kaedah ini mula berkembang pesat dan seterusnya mendapat tempat di kalangan para penyelidik termasuklah dalam bidang-bidang tertentu khususnya perakaunan yang sebelum ini dilihat hanya sesuai menggunakan kaedah kuantitatif.

Dari segi kelebihannya dalam konteks penyelidikan mengenai proses perubahan organisasi, Bryant (2006) menyatakan bahawa kaedah ini memberikan ruang kepada penyelidik dan yang diselidik berada dalam keadaan fleksibel, iaitu membolehkan kedua-dua pihak saling bertoleransi ketika data dikutip dan juga diterjemahkan. Selain itu, Bryant juga berpendapat bahawa melalui kaedah ini maklumat penting yang mungkin tidak dikongsikan oleh mana-mana ahli yang diselidik melalui kaedah lain, akan lebih mudah diperoleh. Ini berdasarkan pandangan beliau bahawa kaedah ini telah membolehkan seseorang penyelidik berpeluang untuk mendapatkan data atau maklumat yang lebih lengkap, komprehensif, terperinci dan mendalam serta menepati konteks persekitaran kajian. Gilbert et al. (2012), Tsamenyi, Cullen dan Gonzalez, (2006) menyatakan bahawa kaedah kajian kualitatif bersifat 
longitidunal membolehkan penyelidik melihat proses perubahan dari segi kandungan dan juga konteks pada masa yang sama.

Secara ringkasnya dan juga perbandingan antara kaedah kualitatif dengan kaedah kuantitatif seperti yang ditunjukkan dalam jadual di bawah, yang mana ianya diterjemahkan semula melalui hasil kerja asal oleh SBU (2014):

Jadual 1: Perbandingan antara Penyelidikan Kuantitatif dan Kualitatif

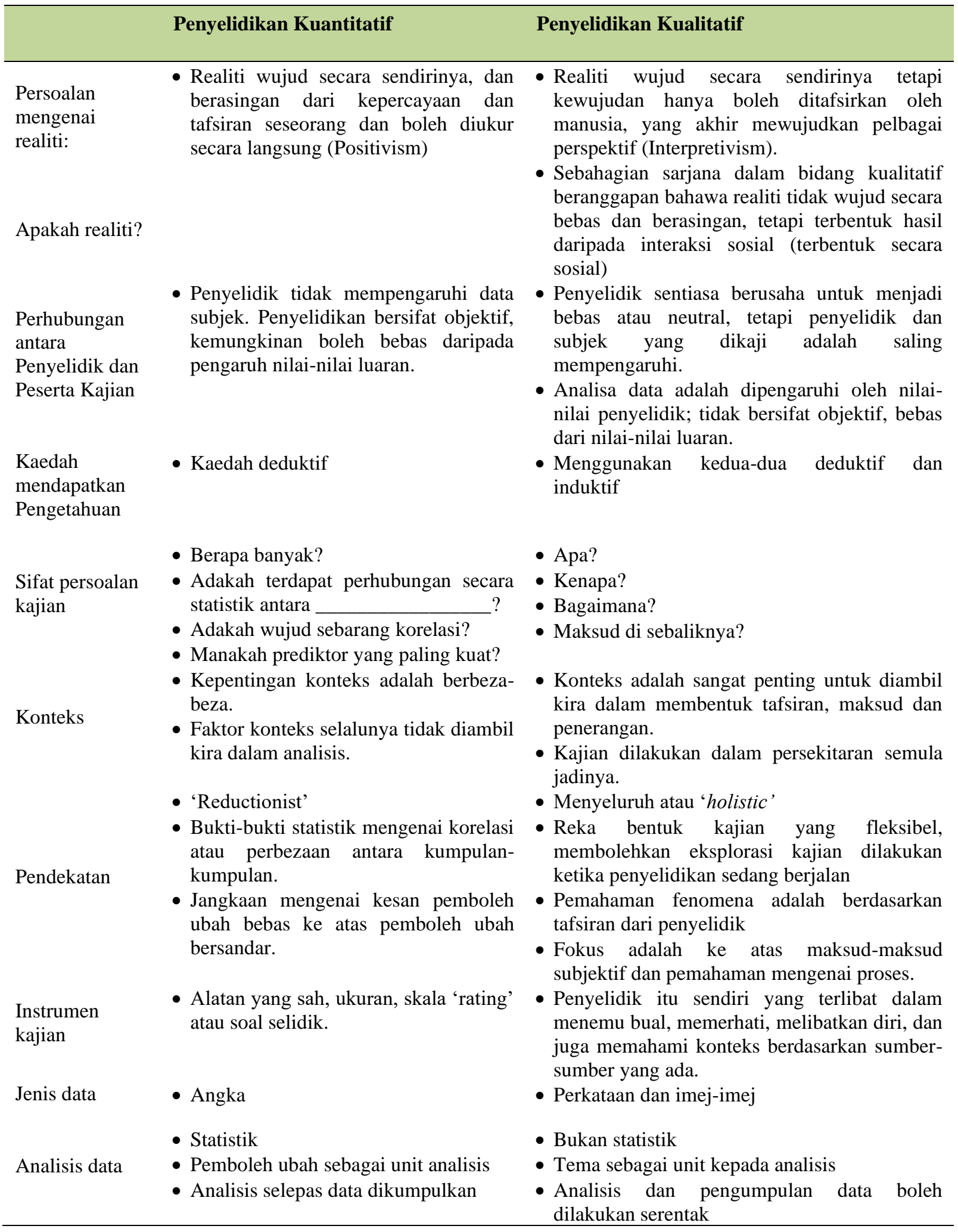


Malaysian Journal of Social Sciences and Humanities (MJSSH), Volume 6, Issue 9, (page 35 - 48), 2021 DOI: https://doi.org/10.47405/mjssh.v6i9.1034

\begin{tabular}{|c|c|c|}
\hline Hasil analisis & $\begin{array}{l}\text { - Statistik deskriptif } \\
\text { - Bukti-bukti statistik mengenai } \\
\text { kewujudan perhubungan antara } \\
\text { pemboleh ubah } \\
\text { - Jangkaan kesan pemboleh ubah bebas } \\
\text { kepada pemboleh ubah bersandar. }\end{array}$ & $\begin{array}{l}\text { - Deskripsi yang 'tebal' dan terperinci } \\
\text { - Kajian berdasarkan klasifikasi, contoh } \\
\text { etnografi, psikologi, sosiologi. } \\
\text { - Pemahaman } \\
\text { - 'Typologies' }\end{array}$ \\
\hline Generalisasi & $\begin{array}{l}\text { - Berdasarkan kebarangkalian } \\
\text { - 'inference' iaitu membuat kesimpulan } \\
\text { berdasarkan dapatan statistik }\end{array}$ & $\begin{array}{l}\text { - inference' iaitu membuat kesimpulan } \\
\text { berdasarkan dapatan statistik } \\
\text { - 'representational' } \\
\text { - Teoritikal }\end{array}$ \\
\hline
\end{tabular}

Sumber: SBU (2014)

\section{Kaedah Kutipan Data dalam Kajian Kualitatif}

\section{Triangulasi Data}

Bryant (2006) dan Bruce (2007) menegaskan bahawa dalam penyelidikan yang melibatkan pemahaman mengenai sesuatu proses perubahan dalam sesebuah organisasi maka penting bagi seorang penyelidik untuk mendapatkan data dari pelbagai sudut khususnya melalui pengalaman dan ingatan individu yang berada dalam organisasi tersebut. Para penyelidik yang menggunakan pendekatan kualitatif, mereka seharusnya menggunakan kaedah yang membolehkan penyelidik mendapatkan data yang 'dalam' dan menyeluruh (Bruce, 2007). Kutipan data atau maklumat dari pelbagai kaedah lain juga adalah sangat penting untuk memastikan dapatan yang diperoleh adalah berkualiti tinggi (Turner, 2010). Ini adalah selaras dengan pendapat Bruce (2007) yang menjelaskan bahawa terdapat desakan agar para penyelidik khususnya penyelidikan kualitatif untuk memastikan data yang dikutip bersifat telus dan jelas. Pada masa yang sama, Onwuegbuzie, Leech dan Collins (2010) juga menyatakan bahawa pada era abad ke21 ini, penyelidikan bersifat kualitatif seharusnya menggunakan kemajuan teknologi terkini dan kaedah-kaedah kutipan data yang lebih inovatif untuk memastikan data yang diperoleh bersifat komprehensif. Sebagai contoh, Onwuegbuzie et al. (2010) mencadangkan agar penyelidik menggunakan teknologi komputer dan rakaman video dalam kaedah pemerhatian dan penglibatan mereka dalam organisasi yang dikaji.

Oleh itu, para pengkaji yang menggunakan kaedah kualitatif mencadangkan agar kajian atau penyelidikan seumpama ini haruslah mendapatkan data dan maklumat yang berkaitan melalui pelbagai kaedah termasuk melalui temu bual, kajian dan penelitian dokumen arkib, pemerhatian di lokasi, pembabitan dalam mesyuarat yang berkaitan. Menurut Yeasmin dan Rahman (2012), pendekatan kutipan data yang menggabungkan beberapa kaedah dipanggil kaedah 'triangulasi'. Yeasmin dan Rahman (2012) mendefinisikan triangulasi sebagai satu kombinasi dua atau lebih teori, sumber-sumber data, kaedah atau penyelidik dalam satu kajian fenomena untuk mendapatkan kesahihan sesuatu dapatan yang mana ianya boleh diguna pakai dalam kaedah kajian kuantitatif dan juga kualitatif.

Menurut Meijer, Verloop dan Beijeard (2002), Stefura (2014) serta Rabionet (2011), dalam kajian bersifat kualitatif, perkara paling penting yang perlu diambil kira oleh seseorang penyelidik untuk memastikan gambaran sebenar fenomena sosial yang sedang dikaji adalah bersifat sebenar ialah 'kesahihan dalaman' yang juga berkait rapat dengan kredibiliti data dan analisis data (Patton, 1999). Ini termasuklah sebagai contoh telah menggunakan dua atau lebih kaedah kutipan dan analisis data, menggunakan lebih dari seorang penemubual, dan juga menemu bual lebih dari seorang pegawai (Stefura, 2014). Kesahihan dalaman hanya akan diperoleh sekiranya data yang dikutip adalah bersifat komprehensif atau menyeluruh (Mathison, 1988; Meijer et al., 2012; Patton, 1999; Stefura, 2014), dan ianya boleh dicapai melalui kutipan data dari pelbagai sudut atau kaedah, atau apa yang dipanggil sebagai triangulasi. 


\section{Kajian Kes}

Salah satu cabang pendekatan dalam kajian bersifat kualitatif adalah menggunakan pendekatan kajian kes untuk memahami dan menerangkan secara terperinci dan mendalam bagaimana sifat sesuatu isu dan perkara yang ingin difahami. Majoriti para pengkaji yang menggunakan kaedah ini berpendapat bahawa, kajian kes dipilih berdasarkan pandangan bahawa hanya melalui kajian kes sahaja pemahaman dan penerangan mengenai satu proses atau fenomena yang berlaku itu contohnya perubahan sistem dan amalan perakaunan pengurusan dapat dilakukan dengan terperinci dan menyeluruh (Caccia \& Steccoloni, 2006; Gurd, 2008; Namazi, 2013; Tessier \& Otley, 2012). Sebagai contoh, kajian yang dilakukan oleh Eriksson, Holden, Williams dan Delive (2016) mengenai persoalan kenapa dan bagaimana beberapa hospital menggunakan pendekatan tertentu dalam melaksanakan fungsi utama mereka menunjukkan bahawa hanya dengan mengkaji organisasi tersebut secara mendalam dan juga bersama dengan persekitaran atau konteksnya maka persoalan kajian tersebut dapat dijawab dengan jayanya. Dapatan Eriksson et al. (2016) menunjukkan bahawa amalan organisasi setiap kes yang dikaji terbentuk dari interaksi pelbagai faktor persekitaran yang bersifat unik antara satu sama lain. Menurut Cosimato, Torre, dan Troisi (2015), dengan kajian kes interaksi pelbagai faktor luaran dan dalaman organisasi yang terlibat dalam proses perubahan organisasi telah dapat diterangkan dengan lebih terperinci.

\section{Kaedah Temu Bual}

Kaedah utama yang digunakan untuk mendapatkan data dalam kajian ini ialah dengan menggunakan kaedah temu bual separuh berstruktur. Terdapat beberapa jenis kaedah temu bual termasuklah temu bual berstruktur, separuh berstruktur dan terbuka, yang mana masing-masing mempunyai kelebihan dan kekurangannya bergantung kepada persoalan dan objektif penyelidikan yang dibuat (Akbayrak, 2000). Dalam kajian ini, penyelidik telah menggunakan kaedah temu bual separuh berstruktur iaitu tema dan bentuk soalan-soalan asas ditentukan terlebih dahulu sebelum temu bual tetapi pada masa yang sama telah sentiasa terbuka untuk diubahsuai agar sentiasa relevan ketika temu bual dilakukan. Pada dasarnya, soalan-soalan asas yang ditentukan lebih awal dibentuk melalui perbincangan dengan penyelia akademik dengan mengambil kira elemen utama persoalan dan objektif kajian. Pengetahuan yang diperoleh melalui penulisan pemahaman sorotan literatur sememangnya sangat membantu dalam pembentukan soalan asas temu bual penyelidikan ini. Kaedah temu bual separuh berstruktur juga membolehkan individu yang ditemu bual sentiasa terpandu, merasa bebas dan kemungkinan dapat mengutarakan beberapa isu baharu yang sebelumnya tidak diketahui penyelidik serta mudah memahami fokus perbincangan yang diutarakan oleh penyelidik (O'Keeffe, Buytaert, Mijic, Brozovic dan Sinha, 2015). Dalam tempoh kutipan data, penyelidik mendapati bahawa majoriti individu yang ditemu bual memberikan jawapan yang terpesong dari persoalan asas kerana mungkin dipengaruhi oleh latar belakang perkhidmatan dan kehidupan mereka sebelum ini. Penggunaan soalan separuh berstruktur membantu penyelidik memandu mereka untuk sentiasa memberikan pandangan pada persoalan asas temu bual.

Dari sudut kualitatif, Frels dan Onwuegbuzie (2013) serta Dilshad dan Latif (2013) menyatakan bahawa penggunaan kaedah temubual dalam penyelidikan ialah sesuatu yang normal dan paling banyak digunakan. Menurut Cosimato et al. (2015), pengumpulan data melalui kaedah temu bual telah memudahkan penyelidik mendapat data yang terperinci, kaya dan sangat bererti (Frels \& Onwuegbuzie, 2013; Dilshad \& Latif, 2013; Rabionet, 2011; Turner, 2010) contohnya untuk data yang berkaitan dengan perubahan amalan perakaunan di dalam organisasi. Data atau maklumat yang diperoleh melalui temu bual telah membolehkan penyelidik mendapat gambaran mengenai realiti isu yang sedang dikaji dari kaca mata dan pengalaman peserta yang terlibat dalam kajian tersebut (Dilshad \& Latif, 2013; Rabionet, 2011). Ini selaras dengan pendapat Malhotra dan Hinings (2015) yang menyatakan bahawa kaedah kutipan data melalui temu bual membolehkan penyelidik mengetahui bagaimana mekanisme perubahan organisasi dapat diketahui termasuklah arah tuju dan momentumnya. Melalui temu bual juga, penyelidik berpeluang mendapatkan maklumat yang lebih dalam mengenai persepsi, pandangan, sikap, tingkah laku, pengalaman dan kepercayaan ahli-ahli organisasi yang dikaji (Evaluation Briefs, 2009:1). Dalam kajian ini, penyelidik boleh mengenal pasti individu yang sesuai 
ditemu bual yang mewakili pelbagai latar belakang perkhidmatan khususnya dari segi tempoh perkhidmatan, bidang dan penempatan perkhidmatan.

Dari segi bilangan yang ditemu bual pada setiap sesi temu bual, penyelidik pada kebiasaannya akan menggunakan kaedah temu bual secara individu dan juga berkumpulan (juga dikenali sebagai kumpulan fokus). Dalam kumpulan fokus ini, penyelidik boleh atau biasanya akan memilih ahli kumpulan dari kalangan pegawai yang berada dalam kedudukan perjawatan dan pangkat yang sama agar mereka lebih mudah bersifat telus dan merasa bebas memberikan pandangan dan maklum balas. Temu bual seperti ini adalah saling melengkapi dari segi kualiti dan kuantiti maklumat yang dikehendaki. Menurut Dilshad dan Latif (2013), penyelidik haruslah mengambil kira beberapa faktor seperti kualiti, masa, ciri-ciri dan sensitiviti soalan atau isu dalam menentukan kesesuaian temu bual individu atau secara berkumpulan. Dilshad dan Latif (2013) juga menambah bahawa untuk soalansoalan yang bersifat sensitif (Barriball, 1994; Rabionet, 2011), atau sekiranya penyelidik berada dalam keadaan tidak pasti mengenai perkara asas mengenai isu-isu tertentu yang penting, maka lebih sesuai bagi penyelidik untuk menggunakan kaedah temu bual berkumpulan berbanding temu bual secara individu.

Pada dasarnya, soalan-soalan yang dikemukakan dalam temu bual untuk kajian ini akan dibentuk berdasarkan idea-idea yang diperoleh melalui sorotan literatur di samping mengambil kira konsepkonsep utama yang membentuk sesuatu teori dan konsep yang digunakan sebagai panduan atau sandaran dalam proses penyelidikan. Seperti yang dicadangkan oleh Akbayrak (2010) dalam mendapatkan data yang berkualiti, penyelidik perlu memastikan agar menemu bual ahli organisasi yang tepat dan bersesuaian dari segi pengalaman dan bidang kerja yang disandang.

Owen (2014) mencadangkan agar penyelidik membahagikan soalan-soalan temu bual kepada tiga kategori iaitu (1) soalan-soalan utama yang menjawab persoalan kajian, dan (2) soalan-soalan susulan dan yang bertujuan mendapat maklumat lebih lanjut berkenaan soalan-soalan utama, dan (3) soalansoalan pengukuhan yang bertujuan untuk memastikan soalan-soalan dalam (1) dan (2) sahih dan tepat. Seperti yang dicadangkan oleh Rabionet (2011), untuk memastikan bahawa data yang diperoleh adalah berkualiti maka penyelidik haruslah melakukan ujian kualiti soalan yang telah direka bentuk dengan menjalankan temu bual rintis terlebih dahulu. Rabionet (2011) dan Turner (2010) menyatakan bahawa temu bual rintis ini membolehkan penyelidik mengenal pasti kekurangan yang masih terdapat dalam reka bentuk temu bual termasuk soalan-soalan temu bual selain dapat mengenal pasti perkataanperkataan yang mungkin sukar atau sensitif kepada para peserta dalam kajian tersebut. Selain itu, Rabionet (2011) juga mencadangkan agar penyelidik menggunakan pita rakaman untuk memastikan tiada sebarang data atau maklumat yang penting tertinggal sekiranya temu bual tersebut direkodkan atau dicatit dengan kaedah lain. Ini selaras dengan cadangan Onwuegbuzie et al. (2010) mengenai inovasi dan penggunaan teknologi dalam mengumpul data oleh penyelidik. Dalam kajian atau penyelidikan ini, penyelidik telah menggunakan temu bual rintis terlebih dahulu sebelum melakukan temu bual yang menyeluruh. Kajian ini mendapati temu bual rintis sangat membantu untuk mereka bentuk semula soalan-soalan temu bual asal yang telah dibentuk khususnya pengubahsuaian dari segi kesesuaian ayat dan perkataan atau terminologi yang digunakan.

Sejurus selepas proses temu bual, penyelidik adalah digalakkan untuk menulis semula dalam bentuk transkrip untuk lebih memahami data yang telah diperoleh, selain untuk ditunjukkan atau dirujuk kembali kepada individu yang telah ditemu bual sebagai pengesahan (Turner, 2010). Walau bagaimanapun, seperti yang ditekankan oleh (Mason, 2010), bilangan individu yang ditemu bual bergantung kepada sehingga data atau maklumat telah menjadi 'tepu', iaitu temu bual seterusnya tidak lagi memberikan maklumat baharu yang relevan (Mason, 2010). Walaupun Mason (2010) mencadangkan agar bilangan peserta yang ditemu bual tidak kurang daripada 15 orang dan sebaikbaiknya di antara 30 hingga 50 orang.

\section{Isu dan Cabaran dalam Proses Kutipan Data}

Berdasarkan kajian yang telah dilakukan oleh Rimando et al. (2015) menunjukkan bahawa walaupun seseorang penyelidik itu memahami bagaimana langkah-langkah yang sepatutnya dipatuhi dalam 
proses kutipan data tetapi ianya tidak akan menjanjikan kuantiti dan kualiti data yang diperoleh itu mencukupi atau memuaskan dan pastinya akan menghadapi beberapa masalah atau cabaran (Dearnley, 2005; Nicholl, 2010). Rimando et al. (2015) seterusnya menerangkan bahawa ini boleh berlaku disebabkan oleh beberapa perkara berkaitan penyelidik itu sendiri, individu yang ditemu bual, keadaan persekitaran, lokasi dan lokaliti penyelidikan serta tempoh masa yang diberikan untuk melakukan kutipan data tersebut. Menurut mereka lagi, kemahiran dan pengalaman penyelidik adalah penting walaupun pada akhirnya ini juga bergantung kepada kerjasama yang diberikan oleh individu yang bakal ditemu bual atau diperlukan dalam proses kutipan data tersebut. Rimando et al. (2015) dan Bourne dan Robson (2015) dengan jelas menyatakan bahawa seorang pemberi maklumat yang ditemu bual akan cuba untuk mengelak memberikan maklumat yang diperlukan sekiranya dia merasakan maklumat yang diminta itu adalah bersifat sulit, dan ditambah lagi jika penyelidik itu tidak dapat meyakinkan pemberi maklumat dari sudut kebolehpercayaan dalam hubungan mereka sebagai penyelidik-pemberi maklumat.

Bonevski et al. (2014) dan Ashton (2014) pula menyatakan bahawa cabaran dalam penyelidikan melibatkan kualiti data boleh berpunca daripada kelemahan penyelidik itu sendiri yang tidak memahami mengenai perkara asas yang perlu diketahui mengenai fokus kajian. Rimando et al. (2015) dan Bonevski et al. (2014) juga menyatakan bahawa tempoh masa dan dana yang diperlukan dalam kutipan data dan penyelidikan haruslah mencukupi agar kuantiti dan kualiti data dapat dijamin.

\section{Metod Kajian}

Kajian ini telah dirancang untuk menggunakan kaedah kualitatif dengan menggunakan pendekatan penggunaan kajian kes dan seterusnya menggunakan temu bual separuh berstruktur, kajian arkib atau dokumen, serta temu bual kumpulan fokus. Pendekatan kajian ini adalah berdasarkan tradisi dan kesesuaian yang diperlukan dalam melaksanakan kajian bersifat kualitatif.

Seperti yang diterangkan dalam bahagian sorotan literatur, perkara paling asas yang telah dilakukan oleh kajian ini dalam usaha untuk memastikan objektif kajian tercapai adalah dengan mematuhi dan memenuhi panduan yang digariskan oleh Habermas seperti yang diterangkan dalam Laughlin (1991) ketika melakukan kutipan data menggunakan kaedah kualitatif. Ringkasnya, Laughlin (1991) menekankan mengenai keperluan pihak penyelidik dan yang diselidik untuk saling mengenali dan memahami sebelum, semasa dan selepas proses kutipan data. Ini termasuklah mematuhi panduan khas mendapatkan kebenaran melalui saluran yang betul, saling berkomunikasi dengan jelas dan teratur, dan saling mempercayai dalam proses kutipan data tersebut.

\section{Kajian Kes}

Dalam kajian ini, pendekatan yang dilakukan adalah dengan menggunakan kajian kes. Dalam soal ini, kajian ini telah memilih kajian kes yang terdiri daripada sekumpulan penyelidik yang terdiri dari pelajar-pelajar tahun akhir di Universiti Malaysia Sabah. Pelajar-pelajar ini telah dibahagikan kepada beberapa kumpulan dan diberikan tugasan untuk melakukan kutipan data sepanjang tempoh PKP dilaksanakan iaitu sekitar bulan Mei 2021 hingga bulan awal Julai 2021. Secara keseluruhan, kumpulan pelajar ini terdiri daripada 12 pasukan dan dianggotai oleh 3 hingga 4 ahli setiap satu. Antara ciri utama setiap anggota dalam pasukan ini ialah mereka telah lulus dan memahami kaedah penyelidikan khususnya dalam proses mengutip data secara kualitatif. Pada masa yang sama, mereka juga dipilih berdasarkan pengetahuan mereka mengenai 'subject matter' yang akan ditanyakan kepada organisasi atau entiti yang bakal mereka pilih untuk dijadikan kajian kes bagi mereka. Kumpulan pelajar yang bertindak sebagai penyelidik ini pula telah diberikan taklimat dan panduan dalam proses pengutipan data yang mereka lakukan. Ini untuk memastikan bahawa mereka mempunyai kefahaman yang cukup sebagai penyelidik.

Setiap dari kumpulan penyelidik ini diminta untuk mengenal pasti sekurang-kurangnya sebuah entiti atau organisasi sebagai kajian kes yang beroperasi di Sabah, Malaysia. Kumpulan penyelidik ini telah diminta lebih awal untuk memilih sebuah organisasi terdiri sama ada daripada syarikat berkaitan 
kerajaan (GLC) atau sebuah lagi adalah pertubuhan bukan kerajaan (NGO). Pemilihan ini berdasarkan panduan yang diberikan oleh Seawright and Gerring's (2008) termasuklah dari segi definisi, kesesuaian dan ciri-ciri penting yang perlu dimiliki oleh sesebuah organisasi kajian kes. Kajian ini secara terancang telah menentukan agar terdapat dua organisasi dari latar belakang kewujudan yang berbeza dipilih untuk memudahkan perbandingan di antara kedua-duanya.

\section{Temu bual separuh berstruktur}

Sepanjang perlaksanaan kutipan data oleh kumpulan penyelidik tersebut iaitu dari awal proses sehingga selesai, kajian ini telah menjalankan sesi temu bual secara formal dan informal sekurang-kurangnya satu kali iaitu melibatkan ketua kumpulan mereka. Secara keseluruhan tidak termasuk temu bual formal, kajian ini telah berjaya membuat sebanyak 15 temu bual yang lengkap. Kajian ini mencatit setiap maklumat penting dan relevan yang telah diberikan kerana rakaman perbualan tidak dapat dilakukan. 12 daripada temu bual tersebut dilakukan melalui telefon dan 3 melalui perjumpaan maya (online meeting). Penggunaan kemajuan dan kelebihan teknologi dalam proses kutipan data ini adalah selari dengan cadangan dan pandangan daripada Onwuegbuzie et al. (2010). Seperti yang telah dijangkakan, melalui temu bual ini penyelidik telah dapat memahami isu-isu dan cabaran yang dihadapi oleh kumpulan pelajar ini ketika mereka melakukan proses kutipan data secara pendekatan kualitatif.

\section{Analisis Dokumen}

Selain dapatan data melalui proses temu bual, kajian ini juga telah mendapatkan data melalui analisis dokumen. Ini bertujuan untuk melengkapkan proses triangulasi data seperti yang telah dicadangkan oleh Bryant (2006) dan Bruce (2007). Dokumen yang dimaksudkan dalam kes ini adalah sebarang dokumen-dokumen bertulis yang digunakan atau telah dihasilkan oleh kumpulan penyelidik tersebut sepanjang kutipan data yang mereka laksanakan berlaku. Ini termasuklah laporan dan analisis hasil kajian, lampiran-lampiran penyelidikan dan catatan-catatan perbincangan yang mereka sediakan dalam proses tersebut. Dalam kes ini, kajian ini mendapati bahawa analisis dokumen ini telah menambahkan kuantiti dan kualiti data yang diperlukan untuk kajian ini.

\section{Hasil Kajian}

Melalui analisis data yang diperoleh melalui temu bual dan juga, kajian ini mendapati bahawa terdapat tiga cabaran utama yang dihadapi oleh penyelidik kaedah kualitatif dalam usaha mengumpul data ketikan PKP dan Pandemik Covid-19 sedang melanda. Ini termasuklah (1) kebenaran untuk memasuki organisasi dan seterusnya mendapat kebenaran untuk melakukan kutipan data; (2) mendapat kerjasama sepatutnya dari pemberi maklumat yang telah dikenal pasti; (3) memperoleh kuantiti dan kualiti data yang dikehendaki.

Secara ringkasnya, daripada 12 buah organisasi yang dipilih untuk dijadikan kajian kes oleh kumpulan penyelidik ini ianya terdiri daripada 2 NGO, 2 organisasi komersil iaitu perbankan, dan selebihnya adalah GLC.

\section{Kebenaran Mendapatkan Maklumat}

Seperti yang dimaklumi oleh setiap penyelidik, salah satu etika yang perlu dipatuhi ketika melakukan kutipan data khususnya yang melibatkan sesebuah organisasi adalah dengan terlebih dahulu mendapatkan kebenaran untuk memasuki organisasi dan seterusnya melakukan kutipan data sama ada secara temu bual, pemerhatian, analisa dokumen dan sebagainya. Hasil kajian ini menunjukkan bahawa masalah utama yang dihadapi oleh para penyelidik untuk meneruskan proses kutipan data ialah pada peringkat awal yang dianggap paling kritikal iaitu proses mendapatkan kebenaran dari pihak organisasi yang diselidik khususnya organisasi komersil dan juga GLC. Contohnya, seorang ahli penyelidikan yang ditemu bual menyatakan: 
DOI: https://doi.org/10.47405/mjssh.v6i9.1034

\begin{abstract}
"pada awal usaha kami untuk mendapatkan data untuk penyelidikan ini kami merasakan yang ianya sangat sukar dilakukan kerana tidak ada satu organisasi pun yang telah kami memohon (mendapat kebenaran) memberi maklum balas, kalau ada pun mereka menolak untuk sebarang sesi temubual”.
\end{abstract}

Pengalaman dari kumpulan tersebut juga dihadapi oleh beberapa kumpulan lain, sebagai contoh seorang wakil penyelidik menyatakan ketika ditemu bual iaitu:

"di peringkat awal kerja kami, kami cuba untuk menghantar email kepada organisasi yang kami pilih untuk kutipan data tetapi kami tidak mendapat sebarang maklum balas. Kami terpaksa menggunakan beberapa kenalan yang ada hubungan dengan pihak dalam organisasi untuk membantu kami dari luar. Itupun masih juga sukar”.

Daripada 12 pasukan penyelidik yang telah ditemu bual, satu daripadanya langsung tidak mendapat sebarang kebenaran dan kerjasama daripada pihak organisasi dalam tempoh 3 bulan untuk mendapatkannya. Walau bagaimanapun, agak berbeza dengan organisasi bersifat NGO, kumpulan penyelidik yang memilih NGO ini telah memperoleh kerjasama yang secara relatifnya lebih mudah. Kedua-dua kumpulan penyelidik tersebut menyatakan bahawa mereka hanya menggunakan panggilan telefon untuk mendapatkan kebenaran tersebut, dan seterusnya hanya dikehendaki untuk menghantar surat permohonan disertakan dengan kertas kerja sebagai rujukan mereka.

Untuk kumpulan yang memilih organisasi GLC, kesemuanya telah mendapat kebenaran tetapi dengan syarat yang lebih ketat berbanding dengan kehendak organisasi NGO, iaitu dikehendaki untuk menyertakan surat sokongan rasmi dari pihak Universiti sebagai bukti bahawa kajian tersebut hanyalah bersifat akademik semata-mata. Majoriti kumpulan penyelidik yang memilih GLC juga memaklumkan bahawa mereka terpaksa beberapa kali menghubungi pihak organisasi untuk meyakinkan mereka mengenai tujuan penyelidikan tersebut kerana majoriti juga menyatakan bahawa di peringkat permulaan rata-rata organisasi tersebut akan menolak untuk menjadi kajian kes dengan alasan keadaan PKP dan Pandemik Covid-19 yang tidak menggalakkan.

\title{
Kerjasama Pihak Ditemu bual
}

Seterusnya, cabaran utama yang dihadapi oleh majoriti kumpulan penyelidik ini adalah untuk mendapatkan kerjasama daripada individu-individu dalam organisasi yang telah dikenal pasti sama ada melalui kaedah 'purposive sampling' mahupun melalui kaedah 'snowball sampling'. Setiap kumpulan penyelidik ini memahami bahawa untuk mendapatkan data yang bersifat 'tepu' maka salah satu perkara yang diperlukan adalah mendapatkan maklumat daripada bilangan pemberi maklumat yang cukup dari segi kuantitinya. Walau bagaimanapun, majoriti pasukan penyelidik ini tidak mendapat kerjasama yang cukup daripada pihak ditemu bual walaupun kebenaran untuk melakukan temu bual telah diberikan oleh pihak organisasi terlebih dahulu. Sebagai contoh, salah seorang wakil penyelidik mengatakan:

"kami telah membuat panggilan telefon pada waktu bekerja kepada individu yang telah dikenal pasti untuk ditemubual. Daripada 15 orang yang kami hubungi, hanya 4 orang sahaja yang menjawab panggilan, dan seterusnya hanya 1 orang sahaja yang bersetuju untuk ditemubual. Kemudian kami gunakan cara lain, iaitu menghantar email, kami sertakan contoh soalan yang diajukan... 2 orang sahaja yang memberi maklum balas. Seterusnya, kami mencuba lagi melalui kawan-kawan, tetapi hanya dapat 2 orang tambahan sahaja”.

Salah satu ahli daripada kumpulan penyelidik yang ditemu bual juga menyatakan bahawa mereka mengalami kesukaran untuk mendapatkan kerjasama daripada pekerja-pekerja organisasi yang telah dikenal pasti. Menurut ahli tersebut:

"Kami menghadapi beberapa isu ketika proses mendapat data. Kita maklum pandemik Covid-19 di Malaysia ni makin semakin teruk pada ketika ini, kerajaan pula 
melaksanakan PKP diperketatkan dan perintah berkurung di seluruh Malaysia. Hanya sebahagian sahaja kapasiti pejabat dibenarkan beroperasi. Ini menyukarkan kami untuk menghubungi mereka. Lagipun, birokrasi jabatan juga salah satu masalah yang kami hadapi"

Dapatan dari analisis laporan para penyelidik ini juga menunjukkan bahawa birokrasi jabatan atau organisasi adalah cabaran utama yang mereka hadapi untuk mendapatkan data yang diperlukan. Menurut mereka, secara umumnya individu yang bersetuju untuk ditemu bual memerlukan kebenaran dari ketua jabatan mereka. Untuk mendapatkan kebenaran tersebut bukanlah mudah kerana sebahagian besar ketua jabatan agak sukar dihubungi ketika PKP sedang berjalan. Pada masa yang sama, masa yang diperlukan untuk memenuhi proses mendapatkan keperluan tersebut adalah agak panjang dan tidak menentu. Ringkasnya, faktor masa dan birokrasi yang diperlukan untuk mendapatkan bilangan sesi temu bual yang dikehendaki adalah antara faktor penentu dan akhirnya menjadi satu cabaran yang perlu diatasi dalam proses melaksanakan proses pengumpulan data oleh para penyelidik ketika musim PKP dan pandemik Covid-19 ini.

\section{Kuantiti dan Kualiti Data}

Perkara seterusnya yang dapat diterangkan melalui data yang diperoleh dalam bentuk dokumen, laporan dan temu bual ke atas kumpulan penyelidik yang telah dibentuk tersebut menunjukkan bahawa terdapat perbezaan yang jelas dari segi kuantiti dan kualiti data yang mereka peroleh berasaskan kategori entiti atau organisasi yang mereka telah selidiki. Hasil daripada perbandingan kuantiti data dan kualiti laporan yang disediakan oleh kumpulan penyelidik pada penghujung proses pengumpulan data menunjukkan bahawa kumpulan yang menjadikan organisasi dalam kumpulan GLC di dapati adalah kurang lengkap dan memuaskan dari kuantiti dan kualitinya berbanding dengan organisasi dalam kategori NGO. Salah seorang penyelidik yang menjadikan GLC sebagai unit kes menyatakan:

"masalah utama yang kami lalui ketika cuba mendapatkan maklumat penting berkenaan
focus kajian kami adalah untuk mendapatkan dokumen-dokumen yang mengandungi
maklumat berkaitan dengan sistem kawalan dalam organisasi tu... walaupun kami
gunakan perkataan 'minta tolong' tetapi staf di sana tu cakap tidak ada apa yg dia boleh
buat selagi PKP ini masih dilaksanakan"

Apa yang cuba disampaikan oleh penyelidik tersebut adalah kesukaran untuk mendapatkan data atau maklumat yang diperlukan disebabkan organisasi tersebut hanya membenarkan pekerja-pekerja tertentu sahaja berada dalam bangunan pejabat mereka. Ini membatasi mereka untuk memberikan kerjasama yang baik dalam proses kutipan data tersebut. Sebaliknya pula berlaku ke atas kumpulan penyelidik yang memilih NGO sebagai unit kajian kes mereka. Menurut salah seorang ahli kumpulan penyelidik tersebut, pengerusi atau ketua organisasi NGO tersebut memberikan kerjasama yang cukup baik untuk setiap maklumat yang mereka perlukan termasuklah dokumen-dokumen melibatkan rekodrekod kewangan dan seumpamanya. Begitu juga halnya dengan kerjasama pekerja-pekerja yang bertugas di dalam organisasi NGO tersebut. Contohnya, salah seorang ahli kumpulan penyelidik ini menyatakan:

"Saya ada dengar kumpulan penyelidik lain agak bermasalah untuk mendapatkan maklumat yang mereka perluka. Kami tidak.... malah pengerusi mempelawa kami untuk menelefon dia pada bila-bila masa sekiranya ada maklumat lain yang diperlukan. Jadi agak mudah bagi kami mendapatkan apa yang kami mau (maklumat)"

Jelas di sini bahawa disebabkan oleh faktor kerjasama oleh pekerja organisasi dalam melayan keperluan para kumpulan penyelidik dan ditambah lagi dengan kesukaran untuk mendapatkan kebenaran untuk memasuki premis pejabat atau perniagaan telah memberi kesan ke atas kuantiti dan kualiti data yang dapat dikutip dalam proses pengutipan data penyelidikan. Kesimpulannya, kuantiti dan kualiti data yang diperoleh melalui entiti GLC adalah kurang baik atau memuaskan berbanding dengan melalui entiti NGO. 


\section{Perbincangan}

Dapatan kajian mendapati terdapat isu dan cabaran yang agak berbeza dalam proses kutipan data melibatkan GLC dan NGO dalam konteks kajian menggunakan kaedah kualitatif. Entiti NGO didapati lebih terbuka dan bekerja sama berbanding entiti GLC dalam proses tersebut. Hasil kajian menunjukkan bahawa data yang dikutip daripada NGO adalah lebih komprehensif dan berkualiti berbanding dengan GLC. Ini menunjukkan bahawa, terdapat banyak isu dan cabaran yang dihadapi dalam proses mengumpul data daripada GLC berbanding daripada NGO ketika PKP Covid-19 di Malaysia. Dapatan kajian ini adalah selaras dengan apa yang telah dinyatakan oleh Rimando et al. (2015) mengenai perkara-perkara yang boleh mendatangkan kesukaran atau cabaran dalam proses kutipan data khususnya untuk kajian bersifat kualitatif.

Dapatan kajian ini menggambarkan bahawa walaupun terdapat isu dan cabaran yang jelas ke atas keberkesanan proses kutipan data ketika musim PKP sedang berjalan tetapi ianya juga bergantung kepada jenis entiti atau organisasi yang dijadikan unit kajian kes. Entiti bersifat NGO memberikan cabaran dan kesukaran untuk dalam proses mendapatkan data berbanding dengan entity bersifat GLC. Kemungkinan perkara ini berkait rapat dengan pandangan yang dinyatakan oleh Rimando et al. (2015) dan Bourne dan Robson (2015) berkenaan dengan kerjasama pihak yang dikaji sama ada sebagai individu mahupun sebagai sebuah entiti atau organisasi. Kerjasama ini pula bergantung kepada sifat data yang ingin diperoleh oleh para penyelidik. Pihak yang ditemu bual akan cuba memberikan pelbagai alasan untuk mengelakkan diri mereka dari terlibat untuk memberikan maklumat yang dianggap sulit. Contohnya, dalam dapatan kajian ini penyelidik menyatakan bahawa pihak yang ditemu bual atau yang dikehendaki untuk menyerahkan maklumat yang diperlukan sering menjadikan alasan PKP secara umumnya sebagai sandaran untuk tidak mahu bekerjasama.

\section{Kesimpulan}

Kajian ini cuba untuk memahami dan menerangkan mengenai cabaran yang bakal dihadapi oleh para penyelidik dalam keadaan persekitaran yang bergolak dan tidak normal contohnya PKP yang disebabkan oleh kebimbangan ke atas kesan virus Covid-19. Proses kutipan data yang melibatkan NGO sebagai kajian kes adalah lebih mudah dan kurang cabaran berbanding dengan GLC. Secara umumnya pula, dapatan kajian ini jelas menunjukkan bahawa cabaran dan kesukaran untuk mendapatkan data yang memuaskan dari segi kuantiti dan kualiti ketika PKP adalah jelas dan signifikan. Adalah dicadangkan agar kajian akan datang dalam konteks ini mengambil kira kategori industri dan lokasi unit kajian kes yang dipilih.

\section{Rujukan}

Abdul Rashid, S. M. R., Hassan, F., \& Ahmad, K. (2020). Post Covid-19 Online Business Strategies by Small-scale Entrepreneurs in Malaysia. International Journal of Academic Research in Business and Social Sciences, 10(9), 564-571.

Akbayrak, B. (2000). A Comparison of Two Data Collecting Methods: Interviews and Questionnaires. Hacettepe Universitesi Egitim Fakultesi Dergesi, 18, 1-10.

Ashton, S. (2014). Researcher or nurse? Difficulties of undertaking semi-structured interviews on sensitive topics. Nurse Researcher, 22(1), 27-31.

Bonevski, B., Randell, M., Paul, C., Chapman, K., Twyman, L., Bryant, J.,...Hughes, C. (2014). Reaching the hard-to-reach: A systematic review of strategies for improving health and medical research with socially disadvantaged groups. BMC Medical Research Methodology, 14(42), 1-29.

Bourne, A. H., \& Robson, M. A. (2015). Participants' reflections on being interviewed about risk and sexual behavior: Implications for collection of qualitative data on sensitive topics. International Journal of Social Research Methodology, 18(1), 105-116.

Broadbent, J. \& Laughlin, R. (2005). Organisational and Accounting Change: Theoretical and Empirical Reflections and Thoughts on a Future Research Agenda'. The Journal of Contemporary Accounting and Organizational Change, 1(1), 7-26. 
Bruce, C. D. (2007). Question Arising about Emergence, Data Collection, and Its Interaction with Analysis in a Grounded Theory Study. International Journal of Qualitative Methods, 6(1), 1-12.

Bryant, M. (2006). Talking About Change: Understanding Employee Responses through Qualitative Research. Management Decision, 44(2), 246-258.

Caccia, L. \& Steccoloni, I. (2006). Accounting Change in Italian Local Governments: What's Beyond Managerial Fashion?. Critical Perspectives on Accounting, 17, 154-174.

Cosimato, S. Torre, C. \& Troisi, O. (2015). How to Innovate Management Accounting For Public Sector: An Italian Case Study. Journal of US-China Public Administration, 12(9), 695-705.

Dearnley, C. (2005). A reflection on the use of semi-structured interviews. Nurse Researcher, 13(1), 19-28.

Dilshad, R. M. \& Latif, M. I. (2013). Focus Group Interview as a Tool for Qualitative Research: An Analysis. Pakistan Journal of Social Sciences, 33(1), 191-198.

Eriksson, A., Holden, R. J., Williams, A. \& Delive, L. (2016). A Case Study of Three Swedish Hospitals' Strategies for Implementing Lean Production. Nordic journal of working life studies, 6(1), 105-131.

Foo, L, P., Chin, M. Y., Tan, K. L. \& Phuah, K. T. (2020): The impact of COVID-19 on tourism industry in Malaysia, Current Issues in Tourism. Current Issues in Tourism, 1-5. https://doi.org/10.1080/13683500.2020.1777951.

Frels, R. K. \& Onwuegbuzie, A. J. (2013). Administering Quantitative Instruments with Qualitative Interviews: A Mixed Research Approach. Journal of Counselling \& Development, 91, 184-194.

Gilbert, F, Denis, J. L., Lamothe, L., Beaulieu, M. D., D'Amour, D. \& Goudreau, J. (2012). Reforming Primary Healthcare: From Public Policy To Organizational Change. Journal of Health Organization and Management, 29(1), 92-110

Gurd, B. (2008). Structuration and middle-range theory - A case study of accounting during organizational change from different theoretical perspectives. Critical Perspectives on Accounting, 19, 523-543.

Karim, W., Haque, A, Anis, Z. \& Ulfy, M. A. (2020). The Movement Control Order (MCO) for COVID-19 Crisis and its Impact on Tourism and Hospitality Sector in Malaysia. International Tourism and Hospitality Journal, 3(2): pp.1-07,

Khan \& Hashim. (2020). The Effect Of Covid-19 On Tourism And Hospitality Industry In Malaysia, Resurgence In The Post-Pandemic Era: A Conceptual Criterion. International Journal of Tourism \& Hospitality Review, 7(2), 54-62.

Laughlin, R. (1991). Environment Disturbances and Organizational Transitions and Transformations: Some Alternative Models. Organization Studies, 12(2), 209-232.

Malhotra, N. \& Hinnings, C. R. (2015). Unpacking Continuity and Change as a Process of Organizational Transformation. Long Range Planning, 48, 1-22.

Mason, M. (2010). Sample Size and Saturation in PhD Studies Using Qualitative Interviews. Forum: Qualitative Social Research, 11(3), 1-13.

Meija, P. C., Verloop, N. \& Beijeard, D. (2002). Multi-Method Triangulation in a Qualitative Study on Teachers' Practical Knowledge: An Attempt to Increase Internal Validity. Quality \& Quantity, $36,145-167$.

Mokhtar, Yazid \& Shamsudin (2020). Sustainability of tourism industry in Malaysia. Journal of Postgraduate Current Business Research, ARBN,1-3.

Namazi, M. (2013). Role of the Agency Theory in Implementing Management's Control. Journal of Accounting and Taxation, 5(2), 38-47.

Nicholl, H. (2010). Diaries as a method of data collection in research. Pediatric Nursing, 22(7), 16-20.

O'Keeffe, J., Buytaert, W., Mijic, A., Brozovic, N. \& Sinha, R. (2015). The Use of Semi-Structured Interviews for the Characterization of Farmer Irrigation Practices. Hydrology Earth System Sciences Discussion, 12, 8221-8246

Onwugbuzie, A. J. dan Leech, N. L. \& Collins, K. M. (2010). Innovative Data Collection Strategies in Qualitative Research. The Qualitative Report, 15(3), 696-726.

Owen, G. T. (2014). Qualitative Methods in Higher Education Policy Analysis: Using Interviews and Document Analysis. The Qualitative Report, 19(52), 1-19.

Rabionet, S. E. (2011). How I learned to Design and Conduct Semi-Structured Interviews: An Ongoing and Continuous Journey. The Qualitative Report, 16(2), 563-566. 
Razak, N. A. (2020). Health and Tourism: Implications of COVID-19 Pandemic to the Malaysian Travel and Hospitality Industry. International Journal of Supply Chain Management, 9(4), 663670.

Rimando, M., Brace, A., Parr, T. L., Sealy,D. A., Davis, T. L., Martinez, L. M. \& Christiana, R. W. (2015). Data Collection Challenges and Recommendations for Early Career Researchers. The Qualitative Report, 12(1), 2025-2036.

SBU. (2014). Evaluation and synthesis of studies using qualitative methods of analysis. Stockholm: Swedish Agency for Health Technology Assessment and Assessment of Social Services (SBU).

Shah, A. U. M., Safri, S. N. A., Thevadas, R., Noordin, N. K., Rahman, A. A., Sekawi, Z., Ideris, A. and Hameed Sultan, M. T. H. (2020). COVID-19 outbreak in Malaysia: Actions taken by the Malaysian government. International Journal of Infectious Diseases, 108-116.

Stefura, G. (2014). Using Methodological Triangulation to Study the Individual Compliance Behaviour towards Income Reporting. SEA - Practical Application of Science, 11(3), 582-587.

Tahajuddin, S. (2021). The Malaysian Experience on Covid-19 Pandemic: The Articles Review and Potential Research Opportunities from the Organizational and Accounting Perspectives. International Journal of Advances in Engineering and Management, 3(1), 755-783. DOI: $10.35629 / 5252-0301248253$

Tahajuddin, S. and Sulaiman, N. N. (2021). Malaysian Government Choice of Fiscal and Monetary Policies during Covid-19 Pandemic: Preliminary Insight. International Journal of Advances in Engineering and Management, 3(1), 248-253.

Tessier, S. \& Otley, D. (2012). From Management Controls to the Management of Controls. Accounting, Auditing and Accountability Journal, 25(5), 776-805.

Tsamenyi, M., Cullen, J., \& Gonzalez J. M. G. (2006). Changes in Accounting and Financial Information System in a Spanish Electricity Company: A New Institutional Theory Analysis. Management Accounting Research, 17, 409-432.

Turner, D. W. (2010). Qualitative Interview Design: A Practical Guide for Novice Investigators. The Qualitative Report, 15(3), 754-760.

Yeasmin, S. \& Rahman, K. F. (2012). Triangulation' Research Method as the Tool of Social Science Research. BUP Journal, 1(1), 154-163. 